\title{
A study of the one-year stability of the Michigan Free and Restricted Association Norms'
}

\author{
WILLIAM L, GEKOSKI ANO KLAUS F, RIEGEL \\ UNIVERSITY OF MICHIGAN
}

The stability of all 17 tasks of the Michigan Free and Restricted Association Norms has been tested over a period of a year. Wide differences in stability were observed between tasks but not between stimulus frequencies. Sex differences in stability were noted and comparisons made between one-week and one-year stability.

Word association norms are increasingly applied in studies of verbal behavior. For this reason, information on the stability of association is of importance. A previous study (Gekoskd \& Riegel, 1966) reported the stability of four tasks of the Michigan Restricted Association Norms (Riegel, 1965a, b). Over a one-week period, Superordinate responses were found to have the greatest stability, Free Associations to have somewhat less, Parts less still, and Following Words least of all. In the present study, Ss were retested after a one-year period. Individual and group analyses were performed to investigate the effect of task instruction, stimulus frequency, sex, and length of intertest interval upon stability. Such information is useful for determining the suitability of the Norms for various experimental purposes, as well as for defining reference points to which the distributional overlap of any two experimental groups may be compared, such as may be done for groups varying in age (Rlegel, Riegel, Smith, \& Quarterman, in press), in creativity (Riegel, Riegel, \& Levine, 1966), or in proficiency of first and second language usage (Ramsey, Riegel, \& Riegel, in press).

\section{Method}

Ss, 25 male and 25 female students enrolled at the University of Michigan, were given 33 stimuli selected from the Michigan Norms. There were 21 nouns, six verbs, and six adjectives. Eighteen were of high (AA) and 14 of low (<AA) frequency, according to the general count of Thorndike \& Lorge (1944).

Free associations plus the 16 restricted association tasks of the Michigan Norms were employed. As shown in Table 1, five of the latter have been denoted as logical, six as infralogical (physical), and five as grammatical tasks. Ss responded to each stimulus under each task restriction. Stimuli and tasks were counterbalanced in the test booklets. The first testing was completed in conjunction with the collection of the Michigan Restricted Association Norms. Retesting occurred approximately one year after the initial testing. Further information concerning procedures and results are available in a Technical Report (Gekoski, 1965).

\section{Analysis}

The following measures were used in the analysis: intra-Individual stability (II = percent of intra-Individual agreement in responses between sessions averaged over Ss and stimuli); minimum group overlap (MGO=percent of identical words occurring in the response distributions of both sessions averaged.over stimuli; the lower of the two percentages is always used in the evaluation); group overlaps (GO $1=$ percent of words in the first distributions which also occurred in the second distributions averaged over stimuli; GO 2 =percent of words in the second distribution which also occurred in the flirst averaged over stimuli).

The following simplified example will clarify the three measures. If the word BLADE is given elght times in the first and five times in the second session as a Part to the Stimulus KNIFE, and the response HANDLE occurs three times in the first and four times in the second session, then minimum group overlap (MGO) is $5+3=8$; group overlap for Session 1 (GO 1) is $8+3=11$; and group overlap for Session 2 (GO 2) is $5+4=9$.

Results

For each task the various measures of stabllity are given in Table 1. Significant differences in stability were noted as a function of task instruction but not as a function of stimulus frequency. The amount of group overlap did not differ significantly as a

Table 1. Intra-Individual (II) and Inter-Individual (MGO, GO 1, GO 2) Stability in Percentages as Explained in Text

\begin{tabular}{llccc} 
& II & MGO & GO I & GO 2 \\
\hline Free Associations & 28 & 54 & 67 & 74 \\
Logical Tosks & 30 & 63 & 74 & 74 \\
Superordinotes & 31 & 66 & 75 & 77 \\
Subordinates & 20 & 50 & 64 & 62 \\
Coordinates & 28 & 66 & 70 & 77 \\
Similars & 35 & 68 & 79 & 79 \\
Controsts & 38 & 66 & 78 & 77 \\
Infralogical Tasks & 23 & 56 & 67 & 68 \\
Parts & 24 & 56 & 67 & 70 \\
Wholes & 27 & 59 & 71 & 72 \\
Locations & 31 & 59 & 72 & 71 \\
Precedings & 25 & 59 & 69 & 69 \\
Succeedings & 16 & 50 & 62 & 62 \\
Contemporaneities & 17 & 52 & 60 & 66 \\
Grammatical Tasks & 19 & 48 & 58 & 58 \\
Nouns & 26 & 56 & 65 & 68 \\
Vorbs & 29 & 57 & 66 & 68 \\
Adjectives & 17 & 48 & 59 & 59 \\
Foregoing Words & 13 & 40 & 49 & 49 \\
Following Words & 12 & 39 & 49 & 49 \\
\hline
\end{tabular}


function of test session, thus suggesting that no dramatic growth, development, or restructuring of the associative networks had occurred during the year interval. On each measure of stability logical tasks were highest, infralogical and Free Associations were lower, and grammatical tasks were lowest. However, there was considerable overlap among these categories. Males showed significantly greater stability than females. Comparisons with data from the study of one-week stability showed slightly lower interindividual stability for the one-year than for the oneweek retest group; intra-individual stability was considerably lower for the one-year retest group. The latter findings are apparently an indication that each individual undergoes greater changes over a long period of time than does a large and relatively homogeneous group of $\mathrm{Ss}$. The absolute magnitude of stability can be regarded as sufficient for most experimental applications. Information on differences in stability among tasks will prove useful in investigations presently underway of the relevance of various dimensions of meaning to the analysis of associative structure.

\section{References}

Gekoski, w. L. An investigation of the one-year stability of the
Michigan restricted association norms. Rep. No. 6, USPHS Grant MH 07619, University of Michigan, 1965.

Gekoski, W. L., \& Riegel, K. F. A study of the one-week stability of the Michigan restricted association norms. Psychol. Rep., 1966, 18, 397-398.

Ramsey, R. M., Riegel, K. F., \& Riegel, Ruth M. A comparison of first and second language leaming of American and Spanish students. J. verbal Learn. verbal Behav., (in press).

Riegel, K. F. The Michigan restricted association norms. Rep. No. 3, USPHS Grant MH 07619, University of Michigan, 1965a.

Riegel; K. F. Free associative responses to the 200 stimuli of the Michigan restricted association norms. Rep. No. 8, USPHS Grant MH 07619, University of Michigan, 1965b.

Riegel, K. F., Riegel, Ruth M., \& Levine, R. S. An analysis of associative behavior and creativity. J. Pers, soc. Psychol., $1966,4,50-56$.

Riegel, K. F., Riegel, Ruth M., Smith, Helen E., \& Quarterman, Carole J. Developmental differences in word meaning and semantic structure. Hum. Develpm., (in press).

Thorndike, E. L., \& Lorge, I. The teacher's word book of 30,000 words. New York: Bureau Publ., Teachers College, Columbia University, 1944.

\section{Note}

1. This research was supported by USPHS Grant MH 07619 to Dr. Klaus F. Riegel. 